\title{
THE ANTI-TERRORIST FUNCTION OF THE STATE AND THE PROBLEM OF "PREVENTIVE" COORDINATION
}

\author{
Denis S. Mits \\ Parliamentary Assembly of the Collective Security Treaty Organization (CSTO), \\ Saint Petersburg, Russian Federation
}

\begin{abstract}
Introduction: the new legal institutions and technologies in the field of counter-terrorism are a matter of great importance for the theory of state and law; in this connection the author of the paper set the aim to study the formation, evolution and unification of this legal trend. Methods: the methodological framework for this study is a set of methods of scientific knowledge, among which the main ones are the methods of systematicity and analysis. Results: the author's point of view grounded in the work is based on the antiterrorist legislation and the opinion of the competent scientific community on the issue of improving the antiterrorist function of the state at a discrete level (with a set of values for different sets of legal arguments) and the regulatory level (with a set of qualitative values of parameters of all the criteria). Based on the legal analysis of the anti-terrorist function of the state, the most popular are the coordination of the fight against terrorism and coordination to minimize the harmful consequences of terrorist manifestations. The topical blocks of issues are raised: I. features of the function system: 1) coordination preventive antiterrorist technology, 2) coordination and human will, 3) international law and selfdefense; II. transformation of terrorism manifestations and conceptual approach to counter- terrorism: 1) international self-defense, 2) modernization of statehood, 3) complex character of prevention; III. appropriateness of anti-terrorist reaction: 1) optimal prevention, 2) legal phenomena, 3) law and legislation. Conclusions: the study revealed the role of the coordination preventive anti-terrorist technology. It is established that due to the complexity of the legal registration of preventive tools and many unresolved related matters it is not possible to highlight the effective coordination of terrorism prevention in modern conditions.
\end{abstract}

Key words: security, terrorism, antiterrorist function of the state, terrorism prevention, coordination, international law, modernization, optimization.

Citation. Mits D.S. The Anti-Terrorist Function of the State and the Problem of "Preventive" Coordination. Legal Concept, 2019, vol. 18, no. 3, pp. 50-55. (in Russian). DOI: https://doi.org/10.15688/lc.jvolsu.2019.3.7

УДК 340.12

Дата поступления статьи: 10.06.2019

ББК 67.0

Дата принятия статьи: 30.06 .2019

\section{АНТИТЕРРОРИСТИЧЕСКАЯ ФУНКЦИЯ ГОСУДАРСТВА И ПРОБЛЕМЫ «ПРОФИЛАКТИЧЕСКОЙ» КООРДИНАЦИИ}

\author{
Денис Сергеевич Миц \\ Парламентская Ассамблея Организации Договора о коллективной безопасности (ОДКБ), \\ г. Санкт-Петербург, Российская Федерация
}

\begin{abstract}
Введение: для теории государства и права имеет громадное значение оптимизация новых правовых институтов и технологий в сфере противодействия терроризму, в связи с чем автором в работе поставлена цель - исследование становления, эволюции и унификации данной правовой тенденции. Методы: методолоопирается на антитеррористическое законодательство и мнение компетентной научной среды по вопросу

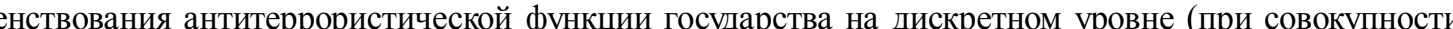
значений при разных наборах правовых аргументов) и нормативном уровне (при совокупности качественных
\end{abstract}


Д.С. Миц. Антитеррористическая функция государства и проблемы «профилактической» координации

значений параметров всех критериев). На основании правового анализа антитеррористической функции государства наиболее востребованными являются координация борьбы с терроризмом и координация по минимизации вредоносных последствий террористических проявлений. Поднимаются актуальные блоки вопросов: 1) особенности системы функции (координационная профилактическая антитеррористическая технология, координация и воля человека, международное право и самооборона); 2) трансформация проявлений терроризма и концептуальный подход к его противодействию (международная самозащита, модернизация государственности, комплексный характер профилактики); 3) адекватность антитеррористического реагирования (оптимальная профилактика, правовые явления, право и законодательство). Выводы: в результате исследования выявлена роль координационной профилактической антитеррористической технологии. Установлено, что из-за сложности правового оформления профилактического инструментария в современных условиях выделить эффективную координацию профилактики терроризма не представляется возможным, в том числе и по причине нерешенности многих смежных проблем.

Ключевые слова: безопасность, терроризм, антитеррористическая функция государства, профилактика терроризма, координация, международное право, модернизация, оптимизация.

Цитирование. Миц Д. С. Антитеррористическая функция государства и проблемы «профилактической» координации // Legal Concept = Правовая парадигма. -2019 . - Т. 18, № 3. - C. 50-55. - DOI: https:// doi.org/10.15688/lc.jvolsu.2019.3.7

\section{Введение}

Наличие политико-правовых конструкций, позволяющих безнаказанно реализовывать свои противоречивые национальные интересы, создает прецеденты для спорных ответных действий, а также деструктивного подражания. Ввиду снижения уровня координации при обеспечении международной безопасности различные мероприятия, связанные с этим, нуждаются в оптимизации с учетом действующего согласованного подхода (в том числе в соответствии с Указом Президента Российской Федерации от 31 декабря 2015 г. № 684 «Об оценке и государственном мониторинге состояния национальной безопасности Российской Федерации»).

Государственная и межгосударственная самозащита возможна при экстраординарных обстоятельствах. Данные обстоятельства не заканчиваются на национальном и наднациональном уровнях, в частности по линии профилактических мероприятий.

Модернизация, то есть упорядочение (оптимизация) и совершенствование государственности, предполагает автономную процедуру. Подобная независимость способствует формированию конструктивных подходов многопрофильного уровня.

Новые технологии профилактики терроризма направлены на раннее предупреждение подобных проявлений. В режиме онлайн данные технологии обеспечиваются посредством устойчивой координации, в частности на плат- формах временных и/или постоянных ситуационных штабов. При этом координация возможна для реализации по локальному профилю (формула: личность - общество - государства) и специальному профилю (общественному и/или государственному).

Таким образом, целесообразно оптимизировать координацию противодействия терроризму до максимально эффективного уровня и на базе аппаратов данного антитеррористического направления по формированию оперативных рабочих групп ситуационной профилактики террористических проявлений.

\section{Особенности функционального реагирования}

Координационная профилактическая антитеррористическая технология (на основании Указа Президента Российской Федерации от 15 февраля 2006 г. № 116 «О мерах по противодействию терроризму») основана на планах, концепциях, стратегиях и прогнозах. Данная система мыслительных и актуализированных действий/операций (юридических и фактических) обеспечивается заинтересованными структурами. В целях получения полезных антитеррористических результатов целесообразно установить соотношения профилактической антитеррористической деятельности. В ходе ее реализации будут оптимально использоваться:

- людские, материальные и финансовые ресурсы; 


\section{ТЕОРИЯ И ПРАКТИКА ГОСУДАРСТВЕННО-ПРАВОВОГО РАЗВИТИЯ}

- средства, техника, приемы и способы;

- методы и правила;

- тактика и профилактические формы;

- стадии производства и режимы реагирования;

- виды контроля (надзора) за координационной профилактической деятельностью ее участников [6, с. 142].

Координация способствует согласованию коллективной и индивидуальной воли. Здесь решается задача соответствия правового обеспечения и воли человека [5, с. 255].

В целом эффективное раннее предупреждение террористических проявлений возможно лишь в ходе оптимизации института прав и свобод человека.

В настоящее время очевидно, что слабая координация снижает общий уровень государственного реагирования на террористические угрозы. При этом отдельные элементы тактики и методики «активной» координации в целях повышения эффективности антитеррористической деятельности включены в категорию закрытой информации. Кроме того, от данного обстоятельства зависит и качество международной антитеррористической координации.

В международном праве механизмы государственной самообороны от терроризма точно не определены, что приводит к негативным последствиям, в частности злоупотреблению данным правом до максимально возможного уровня, то есть реализации оперативно-боевых, тайных и иных операций на территории суверенных государств, где находятся воображаемые террористы [8, с. 160].

Эффективное международное антитеррористическое сотрудничество успешно реализуется лишь в двусторонних государственных форматах. Для поддержания международной безопасности, в частности антитеррористической, важны наработки по формированию и реализации глобальной антитеррористической координации. При этом уже сегодня актуальны согласованные международные антитеррористические обязательства и правовые механизмы ответственности при их неисполнении.

Таким образом, полноценное международное антитеррористическое право будет со временем отличаться от универсального (международного) права.
Развивается проблематика международной самозащиты. Совет Безопасности Организации Объединенных Наций, определяющий возможности данной самозащиты, в современных условиях не востребован. Силовые методы государств применяются без учета установленного порядка [7, с. 121].

«Марионеточная» международная политика по своей сути способствует воспроизводству политико-правовых провокаций для резонанса в целях распространения неурегулированной самозащиты под «ширмой» реализации национальных интересов. Институт международной самозащиты заслуживает должного внимания, в том числе для теории государства и права, но существенные недоработки, имеющиеся в международной правоприменительной практике, вызывают опасение по поводу возможности данного института оказывать содействие в распространении террористических проявлений. Существующее консервативное мнение остерегает законодателя и правоприменителя от формирования и реализации подобных институтов в условиях движения в «правовую крайность».

Переходное состояние современного Российского государства требует дальнейшей модернизации его государственности [1, с. 22]. Позиции модернизации реализуются в полном объеме в связи с отсутствием нормативных ограничителей. Главные смежные вопросы модернизации включают в себя элементы сближения, гармонизации и унификации. Их процедуры формирования успешно заимствуются в ходе модернизации государственности, в частности антитеррористической функции государства.

Важным достижением модернизации государственности является укрепление «эволюции» правового регулирования антитеррористической деятельности. При этом эффективная модернизация государственности позволит выработать комплекс мер, направленных на улучшение антитеррористической функции государства на разных стадиях развития общества.

Современный законодательный комплекс антитеррористических направлений включает в себя (ст. 3 Федерального закона от 6 марта 2006 г. № 35-Ф3 «О противодействии терроризму»): 
1) профилактику;

2) борьбу;

3) минимизацию.

Данный комплексный подход формируется в общем порядке, а реализуется и оптимизируется в пределах функциональных «линий». Комплексный характер мероприятий связан со спецификой узконаправленной проблематики.

При этом в современных условиях поиск унифицированного антитеррористического комплекса становится ответом на новые вызовы и угрозы. Комплекс профилактики терроризма - стратегически важный антитеррористический «арсенал». Однако за недобросовестность его комплектования мерами и наличием «нерабочих» механизмов персональную, а также коллективную ответственность в полной мере должностные лица не несут в связи с неактивностью системы обеспечения в сложных нормативных правовых условиях. В смежных условиях формируется комплекс по координации антитеррористической деятельности.

Отсутствие согласованного подхода в данных стратегических комплексах является новым вызовом для антитеррористической функции государства и ее системы обеспечения и оптимизации.

Комплексный характер антитеррористической функции государства требует активного межведомственного антитеррористического и антиэкстремистского взаимодействия. От их скоординированности зависит антитеррористический потенциал личности, общества и государства. «Через разделение полномочий - к общим законам действий» - формула по созданию эффективных политико-правовых механизмов решения задач, выработки общих позиций и направлений сотрудничества в преодолении этой непростой проблемы [4, с. 71].

Для осуществления профилактики в контексте антитеррористической функции государства необходимо учитывать механизмы регуляции социально полезного поведения:

1) социально-психологические факторы действий;

2) организация правомерной активности человека в социальных группах.

Радикальные преобразования информационного и экономического характера создают социальную трансформацию с отсутстви- ем вектора перемен. Террористическая проблема усиливается ситуацией социальных изменений, рассогласованием социальных ориентиров, психологическим средством социального выбора [3, с. 9].

Слаженная антитеррористическая функция государства на базовом уровне будет способствовать эффективному осуществлению мер, направленных на профилактику терроризма. При этом в современных условиях остается важным использование профилактического аппарата в смежных сферах (Федеральный закон от 23 июня 2016 г. № 182-Ф3 «Об основах системы профилактики правонарушений в Российской Федерации»).

Без профилактической антикриминальной и иной работы выстроить оптимальную профилактику терроризма предоставляется сложно решаемой задачей. Данные «смежные» профилактические комплексы без должного прокурорского надзора могут способствовать нарушению режима законности.

В современных условиях частная (индивидуальная) профилактика целесообразна при ее совершенствовании с учетом вышеуказанных проблем. Следует отметить, что в ходе достижения оптимальной профилактики терроризма два законодательных антитеррористических направления (борьба, минимизация) из вышеуказанных трех будут задействованы в меньшей степени.

Таким образом, сложность развития (в том числе профессионально) оптимальной профилактики терроризма связана с условиями несогласованного укрепления демократии.

Правовые явления, связанные с антитеррористической функцией государства, затруднительно применять без понимания концепта государства и его правовых институтов. Выявление основ функционирования и развития, социальные ценности и назначения предполагают взаимосвязь элементов политической организации общества в современных террористических условиях [2, с. 65].

\section{Выводы}

Спектр правовых явлений в современных условиях влияет на оптимизацию антитеррористической функции государства. При этом отлаженный механизм реагирования на подоб- 


\section{ТЕОРИЯ И ПРАКТИКА ГОСУДАРСТВЕННО-ПРАВОВОГО РАЗВИТИЯ}

ное влияние находится в стадии становления. Важные прецеденты, которые возникают в этой связи, сложно учитывать без соответствующей правовой процедуры. Научное обеспечение системы юридической безопасности формируется согласно общей позиции организационно-правового обеспечения. Без учета динамики воспроизводства террористического сознания в совокупности с низкой правовой культурой правовые вызовы и угрозы не преодолеть силами и средствами указанной системы юридической безопасности.

Экспертное мнение по данной проблематике не до конца нашло поддержку у законодателя и правоприменителя. Антитеррористический правоприменитель сталкивается с различными правовыми проблемами, решение по которым не всегда имеет актуальные результаты.

Правовое обеспечение антитеррористической функции государства формирует актуальный механизм правового противодействия терроризму в системе соответствующего профилактического направления.

В этих процессах более «консервативным» остается законодательное обеспечение, которое под влиянием устойчивой трансформации терроризма смещено в поле оптимизации государственно-правовых стратегий и концепций.

Возможные исключения этой тенденции не всегда объективно воспринимаются отдельными представителями гражданского общества.

Несмотря на разобщенность по смыслу и содержанию, положения подзаконных актов в связи с соответствием ведомственному профилю стали более востребованными формами рассматриваемого правового обеспечения. При этом законодатель естественно опасается включения в антитеррористическую нормативную правовую базу непопулярных профилактических и координационных инструментов. Правоприменитель, в свою очередь, не имеет эффективной рабочей связи с законодателем. Данные антитеррористические субъекты непосредственно связаны с формированием, оптимизацией и реализацией антитеррористической функции государства.

Право и отражающее его антитеррористическое законодательство являются эффек- тивными институтами государственного подавления террористической активности. Законодательство закрепляет правоотношения. Антитеррористические действия, которые не обличены в форму правоотношения, являются по конструкции санкционированием:

1) признание;

2) принятие [2, с. 78].

Правовое обеспечение полноценной безопасности, в том числе в интересах профилактики терроризма, учитывает выработанные подходы любого уровня инициативы.

Следует отметить, что в современных условиях институт международной безопасности утрачивает свою стратегическую значимость. Имеет место затянувшаяся дискуссия в научной среде по актуальным вопросам формирования полноценной безопасности. Однако теория обеспечения международной безопасности имеет как положительные стороны, так и отрицательные.

Решение связанных с этим явлением спорных вопросов не представляется возможным по причине недостаточного практического и теоретического интереса. Динамика согласования различных позитивных процессов важная цель международного сотрудничества, в том числе в целях продвижения тенденций модернизации, которые эффективно влияют на антитеррористическую функцию государства.

\section{СПИСОК ЛИТЕРАТУРЫ}

1. Архипова, Т. Г. Современная российская государственность и перспективы ее модернизации / Т. Г. Архипова // Вестник РГГУ. Серия: История. Филология. Культурология. Востоковедение. 2017. - № 8 (29). - C. 9-23.

2. Бошно, С. В. Государство / С. В. Бошно // Право и современные государства. - 2013. - № 6. C. 64-79.

3. Бошно, С. В. Трудности формирования правовой культуры / С. В. Бошно // Право и современные государства. - 2016. - № 2. - С. 8-10.

4. Кобец, П. Н. Основы выработки концептуальной платформы в решении проблемы защиты молодежи от угрозы проникновения в ее среду экстремизма и терроризма / П. Н. Кобец, К. А. Краснова // Деятельность правоохранительных органов в современных условиях : сб. материалов XXIII Междунар. науч.-практ. конф. - Иркутск : Восточно-Сибирский институт МВД России, 2018. - С. 68-72. 
5. Максуров, А. А. Координация как фактор повышения демократизации правотворчества / А. А. Максуров // Юридическая техника. - 2014.№ 8. - C. 253-255.

6. Максуров, А. А. Координационная юридическая технология как способ минимизации правовых рисков / А. А. Максуров // Правопорядок: история, теория, практика. -2015 . - № 3 (6). - С. 140-142.

7. Фархутдинов, И. З. Превентивная самооборона в международном праве: применение и злоупотребление / И. 3. Фархутдинов // Московский журнал международного права. МГИМО МИД России. - 2016. - № 4 (104). - С. 97-124.

8. Фархутдинов, И. З. Роль международного права в борьбе с международным терроризмом (новая постановка проблемы) / И. 3. Фархутдинов // Государственно-правовое и социальное развитие современного общества: теоретические и практические аспекты : сб. материалов I Междун. науч.-прак. конф. - Грозный : Чечен. гос. ун-т, 2018. - С. 158-161.

\section{REFERENCES}

1. Arkhipova T.G. Sovremennaya rossiyskaya gosudarstvennost i perspektivy ee modernizatsii [Modern Russian Statehood and Prospects of Modernization]. Vestnik RGGU. Seriya: Istoriya. Filologiya. Kulturologiya. Vostokovedenie [Journal of Siberian Federal University. Series: History. Philology. Culturology. Orientalism], 2017, no. 8 (29), pp. 9-23.

2. Boshno S.V. Gosudarstvo [State]. Pravo $i$ sovremennye gosudarstva [Law and Modern States], 2013, no. 6, pp. 64-79.

3. Boshno S.V. Trudnosti formirovaniya pravovoy kultury [Difficulties of formation of legal culture]. Pravo i sovremennye gosudarstva [Law and Modern States], 2016, no. 2, pp. 8-10.

4. Kobets P.N., Krasnova K.A. Osnovy vyrabotki kontseptualnoy platformy v reshenii problemy zashchity molodezhi ot ugrozy proniknoveniya $\mathrm{v}$ ee sredu ekstremizma i terrorizma [Bases of Development of a Conceptual Platform in the Solution of a Problem of Protection of Youth from threat of Penetration into its Environment of Extremism and Terrorism]. Deyatelnost pravookhranitelnykh organov $v$ sovremennykh usloviyakh: Sbornik materialov XXIII Mezhdunarodnoy nauchno-prakticheskoy konferentsii [Activity of Law Enforcement Agencies in Modern Conditions]. Irkutsk, Vostochno-Sibirskiy institut MVD Rossii, 2018, pp. 68-72.

5. Maksurov A.A. Koordinatsiya kak faktor povysheniya demokratizatsii pravotvorchestva [Coordination as a Factor of Increasing Democratization of Law-Making]. Yuridicheskaya tekhnika [Legal Technique], 2014, no. 8, pp. 253-255.

6. Maksurov A.A. Koordinatsionnaya yuridicheskaya tekhnologiya kak sposob minimizatsii pravovykh riskov [Coordination Legal Technology as a Way to Minimize Legal Risks]. Pravoporyadok: istoriya, teoriya, praktika [Law and Order: History, Theory, Practice], 2015, no. 3 (6), pp. 140-142.

7. Farkhutdinov I.Z. Preventivnaya samooborona $v$ mezhdunarodnom prave: primenenie $\mathrm{i}$ zloupotreblenie [Preventive Self-Defense in International Law: Application and Abuse]. Moskovskiy zhurnal mezhdunarodnogo prava [Moscow Journal of International Law], 2016, no. 4 (104), pp. 97-124.

8. Farkhutdinov I.Z. Rol mezhdunarodnogo prava $v$ borbe $\mathrm{s}$ mezhdunarodnym terrorizmom (novaya postanovka problemy) [The Role of International Law in the Fight Against International Terrorism (New Formulation of the Problem)]. Gosudarstvennopravovoe $i$ sotsialnoe razvitie sovremennogo obshchestva: teoreticheskie i prakticheskie aspekty: Sbornik materialov 1 Mezhdunarodnoy nauchnoprakticheskoy konferentsii [State-Legal and Social Development of Modern Society: Theoretical and Practical Aspects]. Groznyy, Chechenskiy gosudarstvennyy universitet 2018, pp. 158-161.

\section{Information about the Author}

Denis S. Mits, Candidate of Sciences (Jurisprudence), Expert, Parliamentary Assembly of the Collective Security Treaty Organization (CSTO), Shpalernaya St., 47, 191015 Saint Petersburg, Russian Federation, a-83@bk.ru, https://orcid.org/0000-0002-6238-8501

\section{Информация об авторе}

Денис Сергеевич Миц, кандидат юридических наук, эксперт Парламентской Ассамблеи Организации Договора о коллективной безопасности (ОДКБ), ул. Шпалерная, 47, 191015 г. СанктПетербург, Российская Федерация, a-83@bk.ru, https://orcid.org/0000-0002-6238-8501 